\title{
Derecho a la ciudad: personas en situación de calle y en riesgo de situación de calle en la Ciudad de Buenos Aires [2017-2019]
}

\section{Veronica Paiva* (D)}

\section{Resumen}

El objetivo de este artículo es analizar el caso de las personas en situación de calle y en riesgo de situación de calle en la ciudad de Buenos Aires, en el período 2017-2019, examinando las causas de ingreso a dicha situación, el tiempo, las estrategias de vida y las redes que implementan para vivir en la calle. También se examina el caso de las personas que viven en hoteles pero que deben concurrir a comedores para alimentarse, dado que sus ingresos no alcanzan para cubrir sus necesidades totales. Dicha situación se analiza en el marco de la noción de Derecho a la ciudad y se examina el alcance de este concepto en el marco de las políticas urbanas neoliberales implementadas en la ciudad de Buenos Aires desde la década de 1990 en adelante. El estudio fue realizado en base a entrevistas en profundidad y observaciones en comedores comunitarios de la ciudad de Buenos Aires. El artículo da cuenta del escenario económico y social que dio origen a estas situaciones y analiza la situación en el marco del concepto de Derecho a la Ciudad y Derecho al Espacio Urbano.

Palabras clave: personas en situación de calle, pobreza urbana, ciudad de Buenos Aires, derecho a la ciudad, hábitat.

\footnotetext{
* Universidad de Buenos Aires, Buenos Aires, Argentina.
} 


\section{Right to the city: the homeless and the risk of homelessness in Buenos Aires, 2017-2019}

\section{Abstract}

The objective of this article is to analyze the case of the homeless and the people at risk of homelessness in the city of Buenos Aires between 2017 and 2019, by examining the causes of entry to this situation, time, life strategies and the networks that they implement to live on the street. The case of people who live in hotels but who rely on soup kitchens to eat will also be examined, since their income is not enough to cover their total needs. This situation will be analyzed in the framework of the notion of right to the city and the scope of this concept will be examined in the framework of neoliberal urban policies implemented in the city of Buenos Aires from the 1990s onwards.

Keyword: homeless, urban poverty, Buenos Aires, right to the city, habitat.

\section{Introducción}

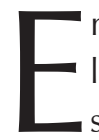

n el año 2010 la Legislatura de la ciudad de Buenos Aires sancionó la ley 3706 de "Protección y garantía integral de las personas en situación de calle o en riesgo de situación de calle" en la cual se tipifica a quienes se considera en dicho estado. Concretamente, a quienes habiten en la calle en forma permanente o transitoria, utilicen o no la red de alojamiento nocturno, a quienes se encuentren en instituciones de las cuales egresen en tiempo determinado, tengan sentencia de desalojo firme o habiten en estructuras temporales o asentamientos, sin acceso a servicios o en condiciones de hacinamiento (Legislatura, 2013). Sin embargo, cuando se analiza el caso de las personas en situación de vulnerabilidad habitacional en la ciudad de Buenos Aires, surge una variedad de casos que no están comprendidos dentro de lo señalado por la ley ya que, aunque estén pernoctando "bajo techo" no están exentos de estar en situación de calle por la alta vulnerabilidad de su condición económica y habitacional, 
con lo cual, el término "situación de calle" excede las circunstancias que señala la Ley 3706.

De acuerdo con ello, los objetivos del texto son: por un lado, ilustrar las diferentes situaciones que viven quienes duermen en la calle, dando cuenta del tiempo en dicho estado, razones, estrategias y redes para sobrevivir en la urbe, como así también el conjunto de fenómenos que no son previstos en la ley, pero que son parte de los casos de vulnerabilidad social y habitacional que aqueja a una parte de la población de la ciudad de Buenos Aires.

¿Cuáles fueron las causas que llevaron a una cantidad de población a pernoctar en la calle?, ¿qué estrategias y redes implementan para llevar adelante su vida cotidiana? ¿qué otras formas de vulnerabilidad habitacional existen y cuál es límite real de la condición de situación de calle?, son los interrogantes que se propone explicar este trabajo.

Respecto de la metodología, cabe decir que el artículo se produjo a partir de una serie de entrevistas tomadas en comedores comunitarios de la Ciudad de Buenos Aires, que dejaron claro que existe un sector poblacional que está al límite de entrar en situación de calle, aunque su cuadro no esté estrictamente contemplado en la ley 3706 y, por tanto, de algunos de los derechos que ésta dispone. Fue a partir de dicho hallazgo, que organizamos la información de las entrevistas de acuerdo con el eje: duerme en la calle/no duerme en la calle, pero con la convicción de que ese criterio es débil y que el hilo que separa ambas situaciones es fino. El hecho de tomar las entrevistas en comedores y que ese sea el elemento aglutinador, también nos otorgó una ventana más amplia para analizar las diversas situaciones de debilidad habitacional en que se encuentra la población de la ciudad de Buenos Aires.

De acuerdo con ello, el contenido del artículo se dispondrá del siguiente modo. En primera instancia, realizaremos un estado de la cuestión que repasa sintéticamente otros trabajos referidos a la temática de "personas en situación de calle" en ciudades de Argentina y otras urbes importantes del mundo, el marco teórico y la metodología utilizada. Luego de ello expondremos algunos datos relativos a la coyuntura social y habitacional 
actual de la ciudad de Buenos Aires, que explica, en buena medida, el incremento de la cantidad de personas en situación de vulnerabilidad habitacional. Luego expondremos los resultados del trabajo de campo y a continuación, algunas conclusiones relativas a la temática.

El trabajo fue realizado en base a veinte entrevistas tomadas en comedores barriales administrados por organizaciones religiosas o políticas a los que asisten las personas que se encuentran en situación de calle o que viven en hoteles. Las entrevistas, realizadas durante los años 2018 y 2019, fueron tomadas con un guión que señalaba el curso del encuentro aunque sin obstaculizar el surgimiento de temas no previstos pero esenciales a la investigación (Taylor; Bodgan, 1987). En cuanto al tratamiento del material recolectado, se trabajó mediante la técnica de análisis de entrevistas, es decir, a partir de un proceso espiralado de tres momentos - descripción -conexión-interpretación - que llegan a resultados cada vez más abstractos, siempre a partir del contenido de las entrevistas (Meo; Navarro, 2009).

\section{Breve estado de la cuestión}

El caso de las personas en situación de calle ha sido investigado para algunas ciudades de Argentina y también en otras ciudades importantes del mundo. Entre las investigaciones relativas a la ciudad de Buenos Aires cabe citar la de Martín Boy (2011) realizada en el período 1997-2011, en la cual analiza las características sociodemográficas de los adultos en la calle, las políticas implementadas por el Gobierno de la Ciudad de Buenos Aires (GCBA) en relación con las necesidades de dicho sector poblacional, los usos que las personas realizan de dichos servicios y sus recorridos por la urbe. En sus conclusiones, Boy describe detalladamente las políticas gubernamentales y afirma que son focalizadas - es decir, actúan paliativamente sobre el problema, pero no sobre sus causas -, describe la relación de los adultos con dichos servicios y señala que los recorridos diarios por la urbe son delimitados, en buena medida, por los tiempos que 
marcan dichas instituciones estatales y de la sociedad civil, tal como los comedores, duchas, paradores.

Otra investigación importante referida a la ciudad de Buenos Aires es la de Paula Rosa (2017), que analiza las organizaciones de la sociedad civil que actúan con las personas que habitan la calle. Rosa establece una categorización de tres tipos: tradicionales, de promoción de derechos y de emprendimientos sociales. Las primeras son, en general, religiosas, dedicadas a la atención de necesidades primarias como comer e higienizarse, con un perfil de voluntariado anclado en la generosidad y la caridad; las segundas se orientan a la promoción de derechos sociales y pretenden no solamente que las personas dejen de ser habitantes de la calle, sino que se cumplan los derechos sociales previstos por la ley; las terceras son aquellas que buscan colaborar con el aprendizaje de oficios para los habitantes de la calle o la generación de emprendimientos que les permitan salir de dicho estado. En su libro Habitar la calle. El accionar de las organizaciones de la sociedad civil en la ciudad de Buenos Aires, además de realizar una reflexión sistemática sobre la forma de relación de estas organizaciones con los habitantes de la calle y con el Estado, Rosa (2017) incluye un capítulo escrito por la antropóloga Griselda Pallares, dedicado a la organización Proyecto 7, que administra el Hogar Monteagudo.

En otro trabajo, Rosa (2013) indaga los modos en que el Gobierno de la Ciudad de Buenos Aires realizó los "conteos" de personas en situación de calle durante el período 1997 - 2010. Afirma que dichos conteos se realizaron mediante el criterio de "punto en el tiempo", es decir, registrando los casos de las personas en situación de calle en un día y hora determinado previamente. Este sistema es muy utilizado internacionalmente, pero tiene varios problemas, entre ellos, el subregistro, dado que cuenta sólo a quienes están durmiendo en la calle el día en que se realiza el recuento.

Siempre en relación con la ciudad de Buenos Aires, Griselda Pallares realizó una tesis donde estudia a las personas sin hogar, a partir de lo cual elaboró el libro Conjugando el presente. Personas sin hogar en la ciudad de Buenos Aires (Pallares, 2004). Allí realiza una extensa revisión de las 
investigaciones referidas a los homeless en Estados Unidos, además de analizar los programas e instituciones del Gobierno de la Ciudad, las redes no gubernamentales de asistencia a las personas sin hogar y las tácticas implementadas por las personas que viven en la calle. Respecto de los programas gubernamentales, explora el "Buenos Aires, Presente" y el "Programa para los Sin Techo" que eran los implementados por el GCBA por aquellos años. Mientras que el Programa Buenos Aires Presente se componía de una línea de atención telefónica (SAT) para responder a las emergencias de las personas en la calle, otra parte de dicho programa, llamado Unidad Móvil de Atención Social (UMAS), respondía con un móvil a la atención planteada por la línea telefónica. Ambas acciones respondían al Programa para los Sin Techo, creado en 1997, que tenía como objetivo la contención inmediata de la salud física y psíquica de la persona en la calle y su alojamiento en alguno de los hogares del GCBA o de la red de organizaciones civiles que trabajan en conjunto con dicho programa, cuya sede era el Hogar Félix Lora. Además de los hogares del Gobierno de la Ciudad, la autora repasa algunos de la red SIPAM (Servicio Interparroquial de Ayuda Mutua), la cual reúne a iglesias católicas, metodistas y anglicanas que administran hogares para personas en situación de calle (Pallares, 2004).

Por su parte, una investigación de Mariana Biaggio también dedicada a la ciudad de Buenos Aires afirma que los beneficiarios de los programas no se identifican con los rótulos de las organizaciones, es decir, ni con el término "sin techo" usado por el GCBA ni con el de "deambulantes" usado por las organizaciones religiosas. Sostiene que los protagonistas se identifican a sí mismos como los "de la calle" y "en la calle" lo cual se vincula a la heterogeneidad que presenta la población que habita la ciudad. Por ejemplo, las personas que han ingresado recientemente no se identifican con los de mayor tiempo, a los que denominan "linyeras". Las personas cercanas a los sectores medios se piensan como sujetos en la calle, diferenciándose de aquellas personas que son de la calle, y tratan de no compartir sus costumbres y códigos en los paradores (Biaggio, 2006). 
En cuanto a otras ciudades de Argentina, Mariel Bufarini (2015) estudió el caso de las personas en la calle en la ciudad de Rosario, en el período 2004-2011. Allí concluye que dichas personas establecen un espacio de referencia desde el que articulan diferentes relaciones, algunas de las cuales derivaron en lazos de vecindad con los que resolvieron situaciones vinculadas a la vida cotidiana. Las personas sin hogar no viven aisladas porque cuentan con allegados con los cuales pueden mantener algún tipo de contacto y porque establecen vínculos cotidianos con distintos sujetos con los que tejen nuevos lazos. Si bien sólo algunos de esos vínculos tienen la suficiente intensidad como para ser consideradas relaciones de amistad, les permiten sobrevivir en la calle y no ser expulsado del espacio de vecindad. Por su parte, el equipo formado por Seidmann y otros tiene varios escritos referidos a la salud y el cuidado de las personas en situación de calle (Seidmann et al., 2017)

En relación con otras ciudades del mundo, existen investigaciones referidas a ciudades de España, Estados Unidos, Inglaterra y otras tantas urbes de perfil semejante. Sobre España puede citarse el trabajo de Santiago Bachiller (2009) que abordó la movilidad forzada de los homeless de Madrid, dando cuenta del accionar de diversos actores que intentan expulsar a las personas en situación de calle de modo violento de ciertos barrios: las fuerzas de seguridad y los movimientos de vecinos. Se trata de vecinos que impulsan proyectos de renovación urbana que no incluyen a esta población empobrecida dentro de los límites de su barrio y por eso propulsan políticas expulsivas violentas y otras más sutiles como instalar los centros de ayuda lejos de los lugares habituales de esta población.

La bibliografía estadounidense sobre el tema es abundante. Entre los muchos trabajos, vale citar a Lovell (1997) que realiza un análisis de la esquizofrenia en personas en situación de calle, por el cual pudo constatar que, a diferencia de las interpretaciones tradicionales sobre la problemática, el discurso del enfermo no es cerrado, sino que entabla diálogo con su entorno inmediato tanto para construir un relato que le permita proteger su "yo", como así también resolver sus necesidades cotidianas y escapar 
de la estigmatización. En cuanto a estudios sobre Londres, puede citarse el informe The homelessnes monitor, el cual señala que la cantidad de personas en la calle del Reino Unido en 2013 era la más alta desde 1990, lo que relacionan con la cantidad de desahucios realizados entre 2008 y 2011 por la imposibilidad de pagar las hipotecas y créditos (Fitzpatrick et al., 2013)

Si bien, como se ha visto, existen varias investigaciones relativas a las personas en situación de calle en la ciudad de Buenos Aires, lo cierto es que no existen tantas que den cuenta de la coyuntura específica de los años 2017-2019, etapa en la que se produjo un aumento significativo de personas en situación de calle. De acuerdo con ello, este trabajo pretende actualizar la información disponible sobre las características de las personas en situación de calle en la ciudad de Buenos Aires en el período 2017-2019 y poner el acento en las condiciones de la coyuntura que provocaron el aumento de la cantidad de personas en esa situación.

\section{Nociones teóricas: derecho a la ciudad y derecho al espacio urbano}

Respecto del marco conceptual desde el cual analizaremos el caso, utilizaremos la noción de derecho a la ciudad acuñada por Henri Lefevbre, en 1968. Se trata de un texto en el cual el autor insta a la clase obrera a opinar y decidir sobre el rumbo que deberá tomar el crecimiento de París, en una época de avance de nuevas obras que derribaban la antigua ciudad y en especial los barrios, a través de lo que Lefevbre (1968) denominaba "museificación". Se trata de revertir el impacto sufrido por las ciudades de economía capitalista, con la conversión de la ciudad en una mercancía al servicio de los intereses de la acumulación del capital. Luego el concepto es retomado por Harvey (2013) en un trabajo en el cual propone a los pueblos que se rebelen contra los modos urbanos impuestos por los promotores inmobiliarios del capitalismo, exigiendo nuevos usos y en especial exigiendo formar parte de las decisiones sobre el uso del excedente del capital. 
Por último, en el año 2004, en el Foro Social Mundial de Quito se sancionó la Carta Mundial por el Derecho a la Ciudad, en la cual se proclaman los derechos de las personas a una ciudad sin discriminaciones de ningún tipo, sean de género, edad, religiosas, étnicas o políticas. Esa Carta supera el criterio tradicional anclado en la mejora de la calidad de vida a través de la vivienda y el barrio, al centrarse en la ciudad y su entorno para proteger a los ciudadanos de la constante urbanización. Consagra los derechos a la vivienda adecuada, al agua potable, a la energía eléctrica, al transporte público, al disfrute de los espacios verdes y a tener participación en las decisiones sobre la ciudad. Busca promover la justa distribución de los beneficios resultantes del proceso de urbanización, la función social de la propiedad; la distribución de la renta urbana y la democratización del acceso a la tierra y a los servicios públicos para todos los ciudadanos, especialmente aquellos con menos recursos económicos y en situación de vulnerabilidad (Foro Social Mundial, 2004).

Este concepto fue ampliado y enriquecido a nivel local, por Oscar Oszlak quien formuló el concepto de derecho al espacio urbano para encuadrar las nuevas situaciones que surgieron a partir del período democrático que comenzó en 1983. En esta instancia el derecho al espacio urbano quedó reformulado como el resultado de las transacciones entre oferentes y demandantes de espacio dentro de la ciudad, en el contexto de políticas de estado que promueven o impiden dichas acciones o facilitan la actuación de alguna de las partes. Así, el derecho al espacio urbano es conceptualizado por Oszlak como el resultado entre tres tipos de acciones: i) las acciones entabladas por actores ubicados de diferente perfil, como por ejemplo oferentes-demandantes o entre los oferentes y el Estado o entre éste y los demandantes; ii) las que implementan actores del mismo perfil: relaciones entre oferentes o entre demandantes o entre agencias estatales entre sí; y iii) el que surge de la relación entre todos esos actores: oferentes, demandantes y Estado. Dado que el derecho al espacio urbano puede ser colectivo, pero también individual, el derecho concreto de cada individuo a tener su lugar dentro del espacio urbano es el resultado de la confluencia específica 
que resulte del encadenamiento entre demandantes, oferentes y políticas públicas y/o leyes (Oszlak, 2018).

Hacia el final del artículo retomaremos estos dos conceptos para analizar el caso de las personas en situación de calle en la ciudad de Buenos Aires.

\section{Coyuntura social y habitacional de la población de la ciudad de Buenos Aires}

En abril de 2019, se realizó un Censo Popular de personas en situación de calle que dio cuenta de la existencia de 7.251 personas en la calle, de las cuales 5.412 dormían en la calle y 1.839 pernoctaban en paradores ${ }^{1}$ del Gobierno de la Ciudad de Buenos Aires o instituciones de la sociedad civil. De ese conjunto de personas, el 52\% afirmó que era la primera vez que estaba en la calle (Ministerio Público de Defensa, 2019). El 80\% eran varones, el 19\% eran mujeres y el 1\% declaró ser travesti o trans. Este censo, que es realizado periódicamente por organizaciones de la sociedad civil, ya había sido realizado en el año 2017 dando cuenta de los siguientes resultados: 4.394 personas en situación de calle efectiva, 1.478 en dispositivos de alojamiento públicos o religiosos y un total de 20.000 en riesgo de estar en la calle debido a desalojos próximos, egresos de instituciones de minoridad etc. Del total de personas en situación de calle, un 23\% había ingresado a dicho estado en el último año, es decir, entre 2016 y 2017. Según ese censo, un $12 \%$ de las personas adultas entrevistadas nació en otros países, un $26 \%$ en otras provincias y un $62 \%$ de los entrevistados nació en el Área Metropolitana de Buenos Aires, con lo cual, queda claro que el incremento de la cantidad de personas en situación de calle que exhibe la ciudad de Buenos Aires en los últimos años se relaciona con el deterioro de las condiciones materiales de vida de la población y no con otros factores tales como la ausencia de lazos devenida de los procesos migratorios de otros países o de localidades dentro del país (Informe..., 2017).

${ }^{1}$ Los paradores son dispositivos del Gobierno de la Ciudad de Buenos Aires para alojar a las personas en situación de calle sólo por una noche renovable cada día. Allí pueden higienizarse, dormir y desayunar. No es permanente. 
Como puede verse, entre 2017 y 2019 se produjo un incremento importante de la cantidad de personas en situación de calle y no existen datos anteriores para evaluar desde cuándo comenzó el ascenso. ¿Cómo se llegó a tal situación? ¿Qué otros cuadros de vulnerabilidad habitacional existen en la Ciudad Autónoma de Buenos Aires (CABA) y qué razones provocaron dicho escenario?

Según nuestro análisis, el aumento de las personas en situación de calle y otros casos de riesgo habitacional se explican por la crisis económica y social que vive la ciudad de Buenos Aires en estos últimos años, en particular, pero cuyo origen puede situarse en la orientación general que ha tomado la política urbana desde la década de 1990 hasta la actualidad.

En este sentido, Rodríguez y Di Virgilio (2014) comentan que desde la década de 1990 se produjo una flexibilidad de las normas urbanísticas y de ordenamiento urbano que permitieron aumentar la edificabilidad en las áreas residenciales, la apertura de corporaciones público privadas que habilitaron la incorporación de suelo e inmuebles del Estado al mercado inmobiliario, la construcción de barrios para sectores de altísimos ingresos y la extensión del crédito inmobiliario a sectores de ingresos altos y medioaltos para la adquisición de viviendas de alto estándar, expandiéndose nuevos estilos de conjuntos residenciales como las torres countries, de acceso restringido y vigilado. Esa misma etapa fue acompañada por políticas urbanas que orientaron el gasto público del estado porteño al sur de la ciudad, creando oportunidades de negocios inmobiliarios en barrios como La Boca o Barracas (Di Virgilio et al., 2004). Otra etapa importante puede situarse hacia el año 2002 en que, como estrategia de salida de la crisis de 2001, se dinamizó el mercado inmobiliario con el incentivo a la construcción de edificios en altura y se continuó con la política de creación de distritos creativos tales como el de Parque Patricios, el distrito del Diseño en Barracas, el de la Comunicación Audiovisual en Palermo y en Chacarita. A grandes rasgos puede decirse que estos proyectos pretendieron revalorizar áreas degradadas y estimular la actividad inmobiliaria y, si bien los autores encuentran diferencias con la gestión urbana de períodos anteriores, 
en tanto las acciones no buscan sólo el embellecimiento urbano sino el fomento social y económico, ellas no rompen con el modelo neoliberal de negocios ya vigente en etapas anteriores (Goicochea, 2015). Durante la década de 1990, en toda la ciudad de Buenos Aires, aumentó el costo del metro cuadrado "promedio" de las viviendas usadas, que era de U\$S 1,185 en 1990, US\$ 1,326 en el 2000, U\$S 1,620 en 2010 y US\$2,333 en 2019 (Continua bajando..., 2019). Según un estudio de la Universidad Argentina de la Empresa, mientras que en octubre de 2017 con dos salarios se compraba un metro cuadrado, en octubre de 2018 hacían falta cuatro salarios (Se duplicó..., 2019).

Los alquileres crecieron tanto como los valores del precio del metro cuadrado. Según informan las estadísticas de la Dirección General de Estadística y Censos del Gobierno de la Ciudad de Buenos Aires, el precio "promedio" del alquiler de un departamento usado de $43 \mathrm{~m}^{2}$ pasó de \$ 1.725 pesos en marzo de $2010^{2}$ a \$ 16.219 en agosto de 2019, es decir, aumentó casi nueve veces su precio en nueve años (Dirección de Estadísticas y Censo del GCBA, 2019). En noviembre de 2017 el costo del alquiler "promedio" por un departamento de dos ambientes era de \$ 7.600 (Alquileres más caros..., 2017) y en 2018 aproximadamente 12.000. Tal como indican los reportes periodísticos, la suba anual de los alquileres había sido del 17\% en 2017 y de más del 30\% en 2018 (El dólar..., 2018). Si bien no hay datos estadísticos relativos a una serie histórica, para 2018 los informes revelaban que la proporción del salario que se destinaba al alquiler superaba el 50\%, duplicando el promedio histórico de 25\% (En CABA..., 2018).

A medida que se hace foco sobre la población más pobre, la situación social y habitacional se complejiza. En el año 2019, el costo de la canasta

${ }^{2}$ En Argentina los alquileres y alquileres de cuartos se publicitan y miden en pesos argentinos. Creo que es mejor mantener la moneda y que el lector pueda imaginar los aumentos a través de medir en un período o relacionarlo con la cantidad de salario equivalente en cada época. El dólar tiene variaciones internas de mercado que impiden que sea válido para medir su impacto en el costo del salario o canasta básica. 
básica total $(\mathrm{CBT})^{3}$, utilizada para delimitar la línea de pobreza, aumentó un 55\% durante el 2019 y sólo en el mes de febrero un 4,3\% por arriba de la inflación promedio del país. De acuerdo con la CBT, que no contempla el alquiler, una familia formada por dos adultos y dos niños necesitó 27.570,43 pesos para no ser pobre (diez mil pesos más que un año atrás), en octubre de 2019 (Pizarro, 2019). Por su parte, los precios de una habitación de hotel en la ciudad de Buenos Aires para una sola persona en 2018, por día, sin baño privado, oscilaba entre los 218 pesos en la provincia de Buenos Aires y los 300 pesos en Ciudad de Buenos Aires, lo cual da un total mensual de entre 6.500 y 9.000 pesos $^{4}$. Una cama en una pieza compartida con otras personas en un hotel ubicado en una avenida céntrica de la ciudad de Buenos Aires costaba \$ 4.000 mensuales en abril de $2019^{5}$ y un cuarto para familia en un hotel del centro de la ciudad de Buenos Aires "sin ventanas y lleno de cucarachas" estaba en 7.900 pesos en marzo de 2019 (Soriano, 2019).

Si se tiene en cuenta que las personas en situación de calle no tienen empleo y que sus magros ingresos provienen de trabajos informales y eventuales como lavar la vereda, limpiar vidrios, descargar camiones por una paga diaria y, en el mejor de los casos, acceder a un empleo no registrado en una garita de seguridad de 8 horas diarias con un sueldo mensual que oscila entre los 9.000 y $10.000^{6}$, resulta claro que es imposible acceder al techo personal aunque éste se remita a un cuarto sin baño privado en la provincia de Buenos Aires. Del mismo modo, si se toma registro de que la asignación universal por hijo, dirigida a uno de los padres desocupados con un total de hasta cinco hijos, estaba fijada en octubre de 2019 en 2.652 pesos por hijo menor de 18 años, resulta evidente que el ingreso

\footnotetext{
${ }^{3}$ En la Argentina la pobreza y la indigencia se miden por ingresos. La CBT tiene en cuesta el costo de la canasta de alimentos, que incluye alimentos y otros bienes como vestimenta, transporte, educación, salud etcétera y la indigencia se mide a través del costo de la canasta básica de alimentos.

${ }^{4}$ Entrevista en comedor parroquial, octubre de 2018.

${ }^{5}$ Entrevista en comedor parroquial, abril de 2019.

${ }^{6}$ Entrevista en Centro San Francisco de Asís, octubre de 2018.
} 
que puede obtener un grupo familiar no alcanza para cobijarse en ningún hotel de la ciudad de Buenos Aires.

Los subsidios monetarios que otorga el Estado para las personas solas o una familia en situación de pobreza o indigencia en la ciudad de Buenos Aires son: la asignación familiar ${ }^{7}$ por hijo o el subsidio habitacional ${ }^{8}$. En este sentido, cabe aclarar que el monto de dicho subsidio alcanzaba en marzo de 2019 "hasta" la suma de 8.000 por 12 meses, lo que, una vez más, deja en claro la falta de relación entre el monto y el costo de un hotel familiar.

Como puede verse, los precios de las diversas opciones habitacionales formales de la ciudad de Buenos Aires tuvieron aumentos del 30\% o más durante el período 2017-2018 y un 31\% en 2019 (Muscatelli, 2019), mientras que el aumento de los salarios fue proporcionalmente mucho menor. Según informa el Instituto Nacional de Estadística y Censo de la Ciudad de Buenos Aires, para el primer trimestre de 2019 el 19,1\% de la población de la ciudad era pobre y el $6 \%$ indigente, lo cual implicaba un 3\% más de pobres y un 1,5 \% más de indigentes en relación con el 2018 (Unas 94 mil..., 2019).

En este cuadro de empobrecimiento paulatino que aflige buena parte de la población de la ciudad de Buenos Aires y desproporción creciente entre el aumento del salario y el valor del metro cuadrado, ya sea para compra o alquiler, resulta claro que el grupo más pobre de la población de la ciudad sufre la versión más cruenta del problema habitacional que se cristaliza en pernoctar en la calle de modo permanente o transitorio o en otros cuadros habitacionales graves. ¿A qué situaciones nos referimos? Damos cuenta de ellas en el punto siguiente.

\footnotetext{
${ }^{7}$ La asignación universal por hijo es una asignación monetaria mensual que se otorga por cada hijo menor de 18 años hasta la cantidad de 5 hijos. Se otorga a desocupados, trabajadores sin aportes, monotributistas sociales, trabajador del servicio doméstico. Lo otorga el Estado nacional.

${ }^{8}$ El subsidio habitacional consiste en un monto mensual que se otorga por 12 meses a quienes estén en situación de desamparo habitacional transitoriamente por desempleo o desalojo. Lo otorga el gobierno de la ciudad de Buenos Aires.
} 


\section{Los que duermen en la calle}

Dentro del grupo de personas que pernoctan en la calle es posible diferenciar tres situaciones: los que están en la calle hace poco, los que lo están hace tiempo, y, dentro de este grupo, los mayores de 60 años.

Entre los que están en situación de calle hace poco, la causa central que los lleva a dicha situación se relaciona con el desempleo, la ausencia de redes familiares y la falta de equilibrio entre los ingresos y el costo de la habitación de hotel. Por ejemplo:

- D., 49 años, hace 15 meses que está en la calle porque se quedó sin el trabajo que realizaba y no tiene familia. Cena en el comedor de una iglesia del barrio de Almagro. No posee subsidio habitacional ni ingresos de ningún tipo. ${ }^{9}$

- R., 24 años, oriundo de San Pablo, Brasil repartía volantes en la calle y ya no tiene más ese trabajo desde hace aproximadamente un año. No tiene familia en Argentina. Los domingos almuerza en un comedor comunitario. Los otros días almuerza o cena en otros comedores o centros de día, en los cuales puede bañarse también. Tampoco posee subsidio habitacional, ni otros ingresos y sus redes se limitan a los conocidos que contacta en los comedores a los que asiste. ${ }^{10}$

- A., 53 años, argentino, se quedó sin trabajo hace cinco meses, tiene familia, pero no pueden ayudarlo porque también están en situación económica crítica. ${ }^{11}$

Entre los que hace tiempo que están en la calle, es posible encontrar personas que registran casi 20 años de vida en situación de calle hasta los tres o cinco años:

- L., 20 años en la calle. Ingresó en dicha situación a partir de una situación crítica. Su esposa tenía problemas con el juego y perdieron el departamento por las deudas. Ella volvió a su provincia de origen y él nunca pudo recuperarse de dicha situación. No tiene trabajo desde hace mucho

${ }^{9}$ Entrevista en comedor barrial, octubre de 2019.

${ }^{10}$ Entrevista en comedor, octubre de 2019.

${ }^{11 E n t r e v i s t a ~ e n ~ c o m e d o r ~ b a r r i a l, ~ n o v i e m b r e ~ d e ~} 2019$. 
tiempo, duerme en la calle dado que no tiene subsidio habitacional, ni ningún otro ingreso. Está enfermo y se está haciendo estudios en el hospital para acceder a un tratamiento. Su rutina cotidiana implica levantarse del sitio donde pernocta, caminar, almorzar en alguno de los dos o tres comedores a los que asiste según el día de la semana, bañarse y asistir a la atención psicológica que recibe en uno de los comedores a los concurre. Siempre duerme en el mismo sitio y allí conoce al encargado del edificio y a algunos vecinos. Generalmente su vida en la calle es tranquila, pero ha vivido hechos de violencia contra su persona. ${ }^{12}$

La situación de las personas mayores de 60 años, que es la edad que la ley de la ciudad de Buenos Aires fija para señalar el inicio de la "tercera edad" fue especialmente indagada en las entrevistas y los resultados fueron los siguientes (en general, todas las personas mayores de 60 años que conectamos en las entrevistas hace mucho tiempo que están en la calle en forma temporal o permanente):

- S., 70 años, varón, estuvo en un hotel hasta hace unos meses, pero lo desalojaron porque el dueño pretendía un monto mucho mayor a lo que él puede pagar con su jubilación. Está en la calle desde hace unos quince años, aunque oscila entre el hotel, la calle o el hogar transitorio del Gobierno de la Ciudad de Buenos Aires. Además de su jubilación, vende chocolates y otras golosinas. Su queja mayor es hacia el hogar de tránsito "hay que hacer todo lo que quiere él" comenta en relación con el administrador del lugar. ${ }^{13}$

- D., mujer, 62 años, hace 20 años que está en la calle. Ingresó a la situación de calle a partir de una estafa por la cual le quitaron su casa y también porque tuvo una enfermedad mental. Vive en la calle y duerme en un hospital. Estuvo en un hogar definitivo para mujeres mayores de 60 años, pero no le gustó porque debía compartir la habitación con otra persona cuyos hábitos le molestaban y dejó el hogar. En este momento no cuenta con ningún tipo de ingresos, pero tuvo subsidio habitacional. Se

${ }^{12}$ Entrevista en comedor comunitario religioso, octubre de 2019.

${ }^{13}$ Entrevista en comedor comunitario religioso, octubre de 2019. 
queja del tipo de hoteles que se pueden pagar con el subsidio: húmedos, fríos y sucios. Prefiere vivir en la calle. Su rutina consiste en dormir en las sillas del hospital, levantarse temprano e ir a la biblioteca, en cuyo baño hasta puede higienizarse. Se alimenta en los comedores de las iglesias y vuelve a pernoctar al mismo hospital en donde puede dejar sus cosas durante el día. ${ }^{14}$

- R., varón, 62 años, vive en la calle junto con un amigo. Hace 15 años que está en la calle. Sucedió luego de un accidente que lo retuvo casi dos meses en el hospital y a partir del cual perdió el empleo y también a su pareja. Tiene tres hijos con los que se conecta periódicamente pero que no pueden ayudarlo para dejar el estado de situación de calle. Tuvo subsidio habitacional y también estuvo en los hogares de tránsito del Gobierno de la Ciudad. Me comenta que, para justificar el subsidio habitacional debe llevar un recibo de alquiler y que le falta uno, por lo cual no le renuevan el subsidio hasta que no lleve ese recibo. Sucede que no siempre le alcanza el monto para alquilar en un hotel y que a veces los sitios que sí podría abonar no poseen recibo formal. Se queja del trato que recibe en las oficinas del Gobierno de la Ciudad - "nos tratan como perros" - y también de la forma de administración de los hogares transitorios. ${ }^{15}$

Entre las personas mayores de 60 años, el tema de la violencia contra los "viejos" surgió espontáneamente en las entrevistas: "ieh viejo, andá a buscar la comida! iEh, viejo movete!". Se quejaba un señor del trato que recibía de los más jóvenes. Del mismo modo, en otra entrevista, un señor se lamentaba de que los jóvenes le hacían gastar el poco dinero de su jubilación en alimentos que ellos necesitaban y que lo discriminaban por su edad. ${ }^{16}$

Los programas del gobierno de la ciudad de Buenos Aires dirigidos a la tercera edad comienzan a partir de los 60 años. Desde ese momento, las personas en situación de calle ya no pueden concurrir a los paradores Bepo Guezzi o al Parador Retiro (hombres) y el Azucena Villaflor (mujeres)

\footnotetext{
${ }^{14}$ Entrevista en comedor, septiembre de 2019.

${ }^{15}$ Entrevista en comedor comunitario, septiembre de 2019.

${ }^{16}$ Entrevista en comedor, septiembre de 2019.
} 
sino que deben concurrir a hogares de tránsito para la tercera edad, tal como el hogar de tránsito para hombres ubicado en el barrio de Barracas o en el hogar de tránsito para mujeres ubicado en el barrio de Monserrat. Ambos hogares tienen una estadía máxima de 100 días. Otras opciones son el hogar de residencia definitiva o el programa Vivir en Casa que consiste en un subsidio que otorga el estado para que las personas mayores de 60 años puedan alquilar su alojamiento.

Tengo 62 años. Estuve de parador en parador. El problema de los paradores de la tercera edad es que hicieron como un monopolio, hay un solo lugar para la tercera edad. Ahora no tengo subsidio habitacional, ahora no lo estoy cobrando. Así que de tanto en tanto voy al hogar transitorio de la calle Osvaldo Cruz. No me gusta estar ahí. [Pero la calle tampoco.] "Acá es una guerra... No es fácil. Acá está durmiendo y te vienen a robar hasta las medias (...) ${ }^{\mathbf{1 7}}$

En síntesis, es posible identificar personas con mayor o menor expertise para sobrevivir en la calle, quienes viven constantemente en ella, quienes alternan entre la calle y el hotel o la calle y el parador, quienes poseen algún ingreso por jubilación o pensión o por realizar alguna pequeña tarea eventual rentada. En ningún caso ese ingreso llega a cubrir el costo de una habitación de hotel o pensión. En el caso de los mayores de 60 años, poseen cobertura específica tal como los hogares transitorios, los definitivos o el programa Vivir en Casa. Aun así, ese soporte no llega a cubrir la demanda actual de alojamiento, además de las quejas sobre el estado de los hoteles y hogares.

\section{Otros casos de vulnerabilidad habitacional: los que duermen "bajo techo" pero asisten a comedores para alimentarse}

Otra situación que surgió del trabajo de campo realizado en los comedores distribuidos en la ciudad de Buenos Aires, que administran las organizaciones religiosas, las asambleas barriales o las organizaciones

\footnotetext{
${ }^{17}$ Entrevista en comedor barrial, septiembre de 2019.
} 
políticas, es la cantidad de personas que tienen donde alojarse, pero deben concurrir a comer o buscan la vianda en los comedores porque no les alcanza el ingreso mensual para cubrir sus necesidades de alojamiento y de alimento. Por ejemplo:

- D., varón, 55 años, hace un año que está en la calle. Trabajaba como seguridad en una garita en donde le pagaban $\$ 7.000$ mensuales. Ahora ya no trabaja allí, pero de todos modos ese dinero no le alcanza para alquilar un cuarto de hotel. Tiene familia, constituida por su madre y hermano, pero no pueden alojarlo porque no poseen espacio suficiente. En este último mes (septiembre de 2019) estaba habitando en un hogar transitorio de la Iglesia Católica en el que puede permanecer por 60 días. Allí puede bañarse, dormir y tiene atención psicológica. Come en los comedores barriales y quisiera trabajar, pero manifiesta que luego de los 50 años no lo toman en ningún lado. ${ }^{18}$

- L., mujer, 60 años, no tiene trabajo ni jubilación. Vive en un hotel que le pagan entre sus cuatro hijos y asiste a una esquina donde entregan viandas para poder alimentarse. De igual modo, la señora R., de 55 años, comenta que se quedó sin trabajo hace un mes, que ahora está durmiendo en la casa de una amiga pero que no sabe cómo hará en el futuro. Otra señora, en la puerta de una iglesia, esperando la comida, comenta que se quedó sin empleo recientemente y que "cuando uno está en la mala" tiene que aguantar. ${ }^{19}$

Este panorama de personas o familias que duermen en hoteles pero que asisten a los comedores a buscar la vianda se repitió en las varias oportunidades durante las entrevistas en iglesias u otro tipo de comedores barriales. Son personas con subsidio habitacional, pero sin otro ingreso, desempleados, jubilados o pensionados con el monto mínimo, ${ }^{20}$ familias o personas solas que se sostienen con ingresos que no alcanzan al monto suficiente para abonar el alojamiento y la comida, para las cuales, por

\footnotetext{
${ }^{18}$ Entrevista en comedor, septiembre de 2019.

${ }^{19}$ Entrevistas en la calle, en la puerta de un comedor de iglesia, octubre de 2019.

${ }^{20}$ Aproximadamente en 11.500 pesos en agosto de 2019.
} 
tanto, la única posibilidad de sostenerse es pagar la habitación de hotel y recoger la vianda en el comedor. En las noches en que concurrí a realizar el trabajo de campo, era posible escuchar las conversaciones de los vecinos que asistían al comedor, que se conocían por hacerlo diariamente y que se contaban mutuamente sus historias. ${ }^{21}$

\section{En síntesis...}

Tal como arrojan los datos estadísticos, la pobreza y la indigencia en la ciudad de Buenos Aires no cesan de crecer desde 2015. Entre 2015 y 2018, la cantidad de pobres creció un 54\% impulsada por la fuerte suba en la cantidad de indigentes. En dicho período se pasó de 314 mil pobres a 441 mil; un 40\% más y de 100 mil indigentes a 198 mil; es decir un 98\% más. En 2018, los pobres e indigentes representaban el $21 \%$ de la población, mientras que en 2015 representaban el 14\%. Estos números crecieron con fuerza entre 2016 y 2018, con una meseta en 2017 (Raed, 2019). Finalmente, entre 2018 y 2019 los pobres pasaron a ser el 19\% de la población y los indigentes el 6\% (Unas 94 mil..., 2019). Este escenario de empobrecimiento tiene una dimensión habitacional que se expresa en el incremento paulatino de las personas en situación de calle que pasaron de ser 4.304 en 2017 a 7.251 en 2019, según el Censo Popular de Personas en situación de calle realizado en ese año. Todo este grupo de personas está contemplado por la Ley 3706 que establece a quienes se considera en situación de calle o en riesgo de estarlo: los que duermen directamente en la vía pública o en paradores u hogares administrados por el Gobierno de la ciudad de Buenos Aires, quienes estén por egresar de instituciones de residencia a tiempo determinado, tengan sentencia de desalojo o pernocten en asentamientos o estructuras temporales.

Sin embargo, como vimos, existe un sector poblacional que no está contemplado en dicha ley pero que, aunque logre sostener la renta de una habitación de hotel, tiene que asistir a los comedores para buscar la comida

${ }^{21}$ Trabajo de campo en iglesia del barrio de Almagro, septiembre-octubre de 2019. 
que les permita alimentarse porque sus ingresos totales no alcanzan para cubrir estas necesidades elementales. Por lo cual, cabe preguntarse, ¿̇cuál es el límite real que señala el ingreso a la situación de calle? ¿Es posible delimitarlo a partir del pernocte en la vía pública o el riesgo de estarlo por egreso de instituciones, desalojo próximo etc.? De acuerdo con lo visto en el trabajo, queda claro que existen muchos más casos de vulnerabilidad habitacional y del riesgo de estar en situación de calle que los que expresa la ley 3706.

Las razones que llevaron a este escenario se relacionan con el incremento de la pobreza y la indigencia en términos monetarios, pero también con la orientación neoliberal que tomó la política urbana de la ciudad de Buenos Aires desde la década de 1990 y que provocó la valorización del suelo de la urbe, el distanciamiento entre el precio del suelo y el monto del salario y entre el precio de los alquileres e ingresos, generando un proceso de "elitización" de la ciudad de Buenos Aires en donde conviven sectores de altos ingresos con otros que se han empobrecido paulatinamente y a los que les resulta cada vez más difícil vivir en ella.

En este cuadro de situación cabe preguntarse ien qué términos es posible referirse al derecho a la ciudad? ¿Son reales los derechos que consagra la Carta de 2004 o son sólo un horizonte deseable pero difícil de concretar? En nuestro parecer, el derecho a la ciudad no es un punto de llegada sino un conjunto de derechos que se dirimen en un escenario específico y que dependen del rol jugado por distintos actores en un contexto específico. En este sentido, el concepto de "derecho al espacio urbano" acuñado por Oslak resulta de mayor utilidad para dar cuenta del caso aquí analizado.

Para este autor, el derecho al espacio urbano surge como resultado de una tensión entre agentes con distinta capacidad de incidencia, en este caso, los demandantes de alojamiento, las políticas públicas, los hoteles y pensiones de la ciudad y el Estado que, por su acción o inacción, constituye un agente fundamental para equilibrar las oportunidades de las diferentes partes. En el contexto específico de la ciudad de Buenos Aires actual, puede 
afirmarse que la inacción del Estado en materia de regulación de los precios de hoteles y pensiones, sus condiciones de higiene y sus pautas de ingreso y permanencia debilitó las posibilidades de la población pobre y vulnerable de la ciudad, que quedó sometida a los arbitrios de los dueños de dichos albergues y a las actividades solidarias y asistenciales de los grupos que recorren la urbe con comida y bebida o a la disponibilidad de lugares en los paradores y hogares administrados por el poder público. Se trata de una política asistencialista y paliativa de parte del estado municipal que no llega a subsanar los efectos de la no intervención en materia de regulación de precios, de modo previo a caer en la situación de vulnerabilidad habitacional.

Verónica Paiva es Doctora en Ciencias Sociales (UBA), docente de Sociología Urbana en la Facultad de Arquitectura, Diseño y Urbanismo de la Universidad de Buenos Aires y investigadora del Centro de Investigación Hábitat y Municipio (CIHAM - UBA).

$\triangle$ vtpaiva@gmail.com

\section{Referencias}

1. ALQUILERES MÁS CAROS: Ios precios subieron hasta un $46 \%$ durante el último año. Diario Clarín. Disponible en: https://www.clarin.com/ciudades/alquilerescaros-subieron-46_0_rylDI8zUW.html.

2. BACHILLER, Santiago. Significados del espacio público y exclusión de las personas sin hogar como un proceso de movilidad forzada. REIS - Revista Española de Investigación Sociológica, n. 128, p. 125-137, 2009.

3. BIAGGIO, Mariana. Linyera, ser o no ser: normas, códigos y estrategias de supervivencia de los hombres de la calle en Globalidad y diversidad. Tensiones contemporáneas. In: VIII Congreso de Antropología Social, Universidad Nacional de Salta, septiembre 2006.

4. BUFARINI, Mariel. Usos del espacio urbano público y políticas sociales. Análisis de la vida cotidiana de las personas sin hogar. Tesis (Doctorado en Humanidades) - Facultad de Humanidades y Artes, Universidad Nacional de Rosario, 2015. 
5. BOY, Martín. Adultos que viven en la calle: políticas públicas, usos y estrategias en torno a la ciudad de Buenos Aires, 2007-2011. Tesis (Doctorado en Ciencias Sociales) - Facultad de Ciencias Sociales, Universidad de Buenos Aires, 2011.

6. CONTINÚA BAJANDO el valor de oferta del usado en Bs As. Reporte Inmobiliario, s/d (2019). Disponible en: https://www.reporteinmobiliario.com/ nuke/article3726-continua-bajando-el-valor-de-oferta-del-usado-en-bs-as.html.

7. DI VIRGILIO, Mercedes; LANZETTA, Máximo; REDONDO, Adriana; RODRÍGUEZ, María Carla. Los procesos de renovación urbana en Buenos Aires: percepciones de habitantes de La Boca. Mundo Urbano, n. 2, 2004. Disponible en: http://www.mundourbano.unq.edu.ar/index.php/ano-2000/38-numero-2-junio/39-2-los-procesos-de-renovacion-urbana-en-buenos-aires-percepcionesde-habitantes-de-la-boca.

8. DIRECCIÓN DE ESTADÍSTICA Y CENSO DEL GOBIERNO DE LA CIUDAD DE BUENOS AIRES. Precio promedio mensual (pesos) de departamentos en alquiler de dos ambientes usados y a estrenar (en base a $43 \mathrm{~m} 2$ ) por barrio. Ciudad de Buenos Aires. Marzo 2010/agosto 2019. Disponible en: https://www. estadisticaciudad.gob.ar/eyc/?p=56521.

9. EL DÓLAR a \$40 reactiva la oferta de propiedades para alquileres temporarios. Apertura Negocios [online]. Disponible en: https:/www.apertura. $\mathrm{com} /$ negocios/El-dolar-a--40-reactiva-la-oferta-de-propiedades-para-alquilerestemporarios-20180904-0009.html.

10. En CABA, donde el salario medio es de $\$ 18.400$, alquilar un tres ambientes cuesta en promedio \$17.200. Nueva Ciudad, 11/09/2018. Disponible en: https:// www.nueva-ciudad.com.ar/notas/201809/38504-en-caba-donde-el-salariomedio-es-de-18400-alquilar-un-tres-ambientes-cuesta-en-promedio-17200. html.

11. FITZPATRICK, Suzanne et al. The homeless monitor: England. Londres: Crisis, 2013. Disponible en: https://www.crisis.org.uk/media/237040/the homelessness_monitor_england_2013.pdf.

12. FORO SOCIAL MUNDIAL. Carta por el Derecho a la Ciudad. Quito: Foro Social Mundial, 2004.

13. GOICOCHEA, María Eugenia. La Ciudad de Buenos Aires como ámbito y objeto de negocios. Reflexiones en torno a la gestión urbana del Distrito Tecnológico Parque Patricios. Quid 16 - Revista del área de Estudios Urbanos, n. 4, p. 161-185, 2015.

14. HARVEY, David. Ciudades rebeldes. Del derecho a la ciudad a la revolución urbana. Madrid: Akal, 2014.

15. INFORME con los resultados del censo popular de personas en situación de calle realizado por organizaciones sociales (CABA). Observatorio del Derecho a la Ciudad, 20/07/2017. Disponible en: https://observatoriociudad. $\operatorname{org} /$ ?s= noticia $\& \mathrm{n}=143$. 
16. LEFEBVRE, Henri. Le droit à la ville. Paris: Éditions Anthropos, 1968.

17. LEGISLATURA DE LA CIUDAD AUTÓNOMA DE BUENOS AIRES. Ley $\mathbf{3 7 0 6 .}$ Protección integral y garantía integral de los derechos de las personas en situación de calle y en riesgo de estar en situación de calle. Boletín Oficial de la Ciudad de Buenos Aires, n. 4207, 02/08/2013.

18. LOVELL, Anne. The city is my mother: narratives of schizophrenia and homelessness. American Anthropologist, v. 99, n. 2, p. 355-368, 1997.

19. MEO, Analía; NAVARRO, Alejandra El uso de la entrevista en la investigación social. La voz de los otros. Buenos Aires: Omicron System, 2009.

20. MINISTERIO PÚBLICO DE DEFENSA. El Ministerio Público de Defensa presentó los resultados del 2do Censo Popular de Personas en situación de calle. Comunicación (sitio institucional), 2019. Disponible en: https://www. mpdefensa.gob.ar/comunicacion/mas-noticias/el-mpd-presento-los-resultadosdel-2deg-censo-popular-personas-situacion.

21. MUSCATELLI, Natalia. El costo de la vivienda. Alquileres: pasar de dos ambientes a tres insume entre 27 y 62\% más. Diario Clarín, 16/11/2017. Disponible en: https://www.clarin.com/economia/alquileres-pasar-ambientesinsume-27- Acceso el 14/10/201962_0_BydRn8o1f.html

22. OSLAK, Oscar. Derecho a la ciudad y derecho al espacio urbano. Voces Revista del Plan Fénix, v. 8, n. 71, p. 7-13, 1991.

23. PALLARES, Griselda. Conjugando el presente. Personas sin hogar en la ciudad de Buenos Aires. Buenos Aires: Sociedad Argentina de Antropología, 2004.

24. PÍREZ, Pedro. Buenos Aires. La orientación neoliberal. Sociologias, v. 18, n. 42, p. 90-118, 2016. https://doi.org/10.1590/15174522-018004204.

25. PIZARRO, Emilse. La odisea de alquilar: cuando la mitad del sueldo se va sólo en la vivienda, Infobae [online], 19/04/2019. Disponible en: https://www.infobae. com/sociedad/2019/04/19/la-odisea-de-alquilar-cuando-la-mitad-del-sueldo-seva-solo-en-la-vivienda/.

26. RAED, Jonathan. En tres años se duplicó la cantidad de indigentes en la ciudad de Buenos Aires, Tiempo Argentino [online], 29/01/2019. Disponible en: https:// www.tiempoar.com.ar/nota/se-duplico-la-cantidad-de-indigentes-en-la-ciudadde-buenos-aires.

27. RODRíGuEZ, María C.; Di Virgilio, Mercedes. Ciudad de Buenos Aires: políticas urbanas neoliberales, transformaciones socio-territoriales y hábitat popular. Revista de Direito da Cidade, v. 6, n. 2, p. 323-347, 2014.

28. ROSA, Paula C. ¿Cuántos son, quiénes son los habitantes de la calle? Acercamientos a las cifras. Trabajo y Sociedad, n. 21, p. 563-577, 2013.

29. ROSA. Paula. Habitar la calle. El accionar de las organizaciones de la sociedad civil en la ciudad de Buenos Aires. Buenos Aires: CEUR-CONICET, 2017. 
30. SE DUPLICÓ la cantidad de sueldos que se necesitan para comprar un metro cuadrado. Apertura Negocios. [online] Disponible en: https://www.apertura. com/negocios/El-dolar-a--40-reactiva-la-oferta-de-propiedades-para-alquilerestemporarios-20180904-0009.html.

31. SEIDMANN, Susana; DI IORIO, Jorgelina; RIGUEIRAL, Gustavo; GUELIO SACCONE, Constanza. El cuidado en personas en situación de calle. Una perspectiva ética y política. Anuario de Investigaciones, v. 23, p. 163-172, 2016.

32. SORIANO, Fernando. El drama de los "sin techo: un censo no oficial registró 7251 personas en situación de calle en la ciudad de Buenos Aires. Infobae [online], 05/07/2019. Disponible en: https://www.infobae.com/sociedad/2019/07/05/ el-drama-de-los-sin-techo-un-censo-no-oficial-registro-7-251-personas-ensituacion-de-calle-en-la-ciudad-de-buenos-aires/.

33. TAYLOR, Steven; BODGAN, Robert. Introducción a los métodos cualitativos de investigación. Buenos Aires: Paidós, 1987.

34. UNAS 94 MIL personas pasaron a ser pobres en la Ciudad de Buenos Aires en el último año. Perfil [online], 16/07/2019. Disponible en: https://www.perfil.com/ noticias/economia/94-mil-personas-pasaron-a-ser-pobres-en-ciudad-de-buenosaires\%20.phtml. 
